\title{
Impact of dissociation on treatment of depressive and anxiety spectrum disorders with and without personality disorders
}

This article was published in the following Dove Press journal:

Neuropsychiatric Disease and Treatment

17 October 2016

Number of times this article has been viewed

\author{
Jan Prasko' \\ Ales Grambal' \\ Petra Kasalova' \\ Dana Kamardova' \\ Marie Ociskova' \\ Michaela Holubova ${ }^{1,2}$ \\ Kristyna Vrbova' \\ Zuzana Sigmundova' \\ Klara Latalova' \\ Milos Slepecky ${ }^{3}$ \\ Marta Zatkova ${ }^{3}$ \\ 'Department of Psychiatry, Faculty \\ of Medicine and Dentistry, Palacky \\ University in Olomouc, University \\ Hospital Olomouc, Olomouc, \\ 2Psychiatric Department, Hospital \\ Liberec, Liberec, Czech Republic; \\ ${ }^{3}$ Department of Psychology \\ Sciences, Faculty of Social Science \\ and Health Care, Constantine the \\ Philosopher University in Nitra, \\ Nitra, Slovak Republic
}

Correspondence: Jan Prasko Department of Psychiatry, Faculty of Medicine and Dentistry, Palacky University Olomouc, University Hospital, IP Pavlova 6, 77520 Olomouc, Czech Republic

Tel +4206034l4930

Email praskojan@seznam.cz
Objective: The central goal of the study was to analyze the impact of dissociation on the treatment effectiveness in patients with anxiety/neurotic spectrum and depressive disorders with or without comorbid personality disorders.

Methods: The research sample consisted of inpatients who were hospitalized in the psychiatric department and met the ICD-10 criteria for diagnosis of depressive disorder, panic disorder, generalized anxiety disorder, mixed anxiety-depressive disorder, agoraphobia, social phobia, obsessive compulsive disorder, posttraumatic stress disorder, adjustment disorders, dissociative/conversion disorders, somatoform disorder, or other anxiety/neurotic spectrum disorder. The participants completed these measures at the start and end of the therapeutic program - Beck Depression Inventory, Beck Anxiety Inventory, a subjective version of Clinical Global Impression-Severity, Sheehan Patient-Related Anxiety Scale, and Dissociative Experience Scale.

Results: A total of 840 patients with anxiety or depressive spectrum disorders, who were resistant to pharmacological treatment on an outpatient basis and were referred for hospitalization for the 6-week complex therapeutic program, were enrolled in this study. Of them, 606 were statistically analyzed. Data from the remaining 234 (27.86\%) patients were not used because of various reasons (103 prematurely finished the program, 131 did not fill in most of the questionnaires). The patients' mean ratings on all measurements were significantly reduced during the treatment. Also, $67.5 \%$ reached at least minimal improvement (42.4\% showed moderate and more improvement, $35.3 \%$ of the patients reached remission). The patients without comorbid personality disorder improved more significantly in the reduction of depressive symptoms than those with comorbid personality disorder. However, there were no significant differences in change in anxiety levels and severity of the mental issues between the patients with and without personality disorders. Higher degree of dissociation at the beginning of the treatment predicted minor improvement, and also, higher therapeutic change was connected to greater reduction of the dissociation level.

Conclusion: Dissociation is an important factor that influences the treatment effectiveness in anxiety/depression patients with or without personality disorders resistant to previous treatment. Targeting dissociation in the treatment of these disorders may be beneficial.

Keywords: depression, anxiety disorders, treatment resistance, panic disorder, GAD, OCD, social phobia, PTSD, adjustment disorders, personality disorders

\section{Introduction}

Pharmacotherapeutic efficacy in the treatment of anxiety disorders, posttraumatic stress disorder (PTSD), obsessive compulsive disorder (OCD), and similar conditions, as well as of major depressive disorder, has been demonstrated by agents from various drug classes (antidepressants, antipsychotics), and, in addition, in anxiety disorder by 
benzodiazepines, and to the $5-\mathrm{HT}_{1 \mathrm{~A}}$ receptor partial agonist, buspirone, and the anticonvulsant, pregabalin. ${ }^{1-7}$ Also, psychotherapy (especially cognitive behavioral therapy [CBT], nondirective supportive treatment, behavioral activation treatment, psychodynamic treatment, problem-solving therapy, interpersonal psychotherapy, and social skills training) proved to be effective in the treatment of anxiety spectrum disorders as well as major depressive disorder. ${ }^{4,8-13}$ A meta-analysis by Cuijpers et $\mathrm{al}^{14}$ compared combined pharmacological and psychological therapy with psychological therapy alone for depression and concluded that the combined treatment was superior in the short term. The same situation is found in anxiety disorders, OCD, and PTSD. ${ }^{4,15,16}$

Treatments for both major depressive disorder and anxiety disorders generally have medium effect sizes, ${ }^{17}$ but observational studies and trials consistently report high rates of nonresponse, ${ }^{18,19}$ with $12 \%-20 \%$ of depressed patients showing no benefit even from multiple courses of treatment. ${ }^{20-24}$ Such a condition is often termed as treatmentresistant depression. ${ }^{25}$ The situation is similar in the treatment of anxiety disorder..$^{4,15,16}$ One of the questions arising is if some psychological factors could influence the efficacy of treatment of resistant patients with anxiety spectrum or depressive disorders.

\section{Dissociation}

In the topic of psychological factors, dissociation demonstrated to be the important element influencing treatment results in patients with depressive and anxiety disorders. ${ }^{26-28}$ The basis of dissociation lies in the splitting off thoughts, feelings, or behavior from normal integrated awareness. ${ }^{29}$ Spiegel has defined it ${ }^{30}$ as "a separation of mental events that would ordinarily be processed together - a discontinuity of memory, diagnostically identity, perception, motor function, or consciousness". It is the ability to isolate certain psychological processes so that they seem to arise autonomously of each other. This lets a person keep out of conscious cognizance of the many everyday experiences that normally he/she would be aware. ${ }^{31,32}$ Dissociated content may be temporarily and reversibly inaccessible to consciousness, but will remain to affect conscious (or other unconscious) experiences and behavior. ${ }^{33}$ Numerous difficulties are created by dissociation: ${ }^{34}$

1. The individual displays unpredictable behavior that is dependent on which dissociated part of the dissociation is prevailing at an actual time in certain circumstances.

2. Dissociation is a cause of tension because the inconsistency within the experiential system disrupts the basic need to retain a stable, coherent implicit conceptual coordination. ${ }^{35}$
3. Intrusions of the nondominant part of the dissociation into a person's consciousness are upsetting and disturbing. The consequence is an unremitting cause of pressure formed by a conflict between sustaining the dissociation and attempting to integrate it.

Also, there is also a nonpathological dissociation. ${ }^{36}$ Dissociation lets us carry out several multifaceted jobs at the same time, such as knitting while watching TV. "Pathological dissociation" usually grows up as a consequence of severe psychotrauma, abuse, or mistreatment. ${ }^{29,33,36-39}$ For example, the symptomatology of PTSDs may characterize the additional form of dissociation insofar as dissociation accounts for a normal reaction to major stress ("I am not here" or "This is not happening to me"). This promotes adaptation under dangerous circumstances.

The majority of investigations have focused on the environmental backgrounds of dissociative dispositions, particularly childhood trauma. It has been established that experience with childhood abuse facilitates the development of dissociative mechanisms. ${ }^{40,41}$ Childhood psychotrauma has been associated with dissociation, and people exposed to childhood abuse show a higher degree of anxiety. ${ }^{42-44}$

Many individuals with anxiety disorders also have some kind of personality disorders (PDs) and experience some degree of dissociation - splitting off the unacceptable weak aspects from the preferred identity. ${ }^{35}$ Persons who have been severely traumatized may use the dissociation much more, separating off the internal aspects of themselves. ${ }^{35}$ The freezing of affect and withdrawal, including unconcern in the future, is an expression of the requirement to continuing the dissociation and avoiding thereby the distress and anxiety formed by attempts at assimilation. ${ }^{34,35,45}$

\section{Comorbid PD}

Other significant characteristics connected with the treatment outcome are comorbidities, particularly with the PDs. A diagnosis of PD frequently evokes images of troublesomeness, demanding work with little hope for success, and this consistently affects the therapist's conscious or unconscious approaches from the start of his relationship with the patient. These attitudes are often negative, moralizing, and rigid. ${ }^{46}$ Most clinicians believe that the occurrence of anxiety disorders or major depression in comorbidity with a PD often leads to longer treatment, worsens the prognosis, and, therefore, increases the treatment costs.

However, the summary of empirical psychotherapeutic studies of PD shows that, despite the myth of untreatability, treatment is relatively effective. For example, Perry and Bond $^{47}$ carried out a meta-analysis showing that positive 
changes in active treatment in patients with PDs are two to four times higher than in controls without any active treatment. In four studies with the outcome treatment criterion of full remission, $52 \%$ of patients met this criterion after 1.3 years of treatment. Even if the progress is not as fast and substantial as for anxiety disorders or depression, there is still a considerable decrease in the patients' misery and improvement in their adaptation in life. This meta-analysis, however, is not able to answer the question: Does comorbid PD affect the treatment effectiveness for any particular disorder? In our study, we found that there was a smaller decrease in specific panic and agoraphobic symptoms during treatment in patients with comorbid PD than in patients without PD. ${ }^{48}$ Nevertheless, there was also a significant reduction in anxiety and avoidance symptoms in patients with panic disorder/agoraphobia comorbid with PD. A high percentage of these patients achieved significant overall improvement. However, there is a dearth of information on comorbidity of PD in the treatment of social phobia. In a 6-week complex therapeutic program with a combination of CBT and antidepressants, Vyskocilova et $\mathrm{al}^{49}$ showed that patients with social phobia and comorbid PD displayed a lesser decrease in specific symptomatology after treatment, when compared to patients with social phobia without PDs. However, a significant reduction in symptomatology occurred in PD patients as well. On the contrary, Kamaradova et $\mathrm{al}^{50}$ proved the efficacy of the complex 6-week treatment program and identified the predictors of therapeutic response to social phobia. There was no statistically significant influence of comorbid PDs on the treatment outcomes. The results of the study in panic disorder were the same; the comorbidity of PD did not affect the treatment efficacy of the 6-week complex therapeutic program. ${ }^{51}$

In Sedlackova et al's ${ }^{52}$ study, the authors recognized that there were no significant differences between the treatment outcomes in depressed patients with and without comorbid PD. Also, other investigations found comorbidity with a PD does not influence the depression treatment. ${ }^{53-56}$ The adverse effect on treatment outcome is more evident in comorbidity of major depressive disorder with two or more PDs. ${ }^{57}$ This double comorbidity may lead to longer time to reach remission. ${ }^{58,59}$ Still, these findings are not in agreement with the studies on psychotherapy. Levenson et al ${ }^{59}$ studied depressive individuals who were cured with interpersonal psychotherapy. The authors found no differences in the outcomes of therapy concerning the occurrence of one comorbid PD (except borderline PD [BPD]). O'Leary and Costello ${ }^{60}$ found that comorbidity with a PD predicted a prolonged time for achieving remission in the treatment of acute depression, but the comorbidity with PD was not a predictor of more frequent relapses in the 18-month follow-up. Individuals with a comorbid BPD had early-onset depression, more depressive episodes, a higher number of previous suicide attempts, higher prevalence of comorbidity with anxiety disorders, and more substance use disorders than the depressed patients without BPD. ${ }^{61}$ Different results obtained regarding comorbid PD may be due to the different assessment methods used, several types of treatment used (only pharmacotherapy, or psychotherapy, various psychotherapeutic approaches, or a different setting), and specifics of the patient (coping strategies, the rate of cooperation, personality characteristics, voluntariness of hospitalization, pharmacoresistance, etc).

\section{Aims of the study and the main hypotheses}

Our group studied the impact of dissociation on the therapeutic change during the last 10 years and published several studies, which confirmed the negative association with treatment outcomes on small samples of patients with OCD, anxiety, and depression disorders. ${ }^{27,28,62}$

The objective of the research was to explore the influence of dissociation on the treatment effectiveness of patients with the anxiety spectrum and depressive disorders, and with or without comorbid PDs. The main hypotheses were

1. During the therapeutic process, there would be improvement in the degree of depression, anxiety, and the severity of the disorder.

2. The responses to the treatment would be different according to the marital status, heredity, and employment status.

3. Patients with various diagnoses respond to the therapy differently.

4. Patients without comorbid PD will improve more than patients with comorbid PD.

5. Higher levels of dissociation at the beginning of the treatment predict minor improvement during the therapy in the degree of depression, anxiety, and the severity of the disorder.

6. The major therapeutic change is connected to the greater reduction of dissociation.

\section{Methods}

\section{Participants}

The research sample consisted of inpatients who were hospitalized in the psychiatric department and met the International Classification of the Diseases - 10th edition (ICD-10) criteria for the diagnosis of the depressive disorder, panic disorder, generalized anxiety disorder, mixed anxiety-depressive 
disorder, agoraphobia, social phobia, OCD, PTSD, adjustment disorders, dissociative/conversion disorders, somatoform disorder, or other anxiety/neurotic spectrum disorder. ${ }^{63}$ The diagnostic criteria of ICD- $10^{63}$ were used as a primary diagnostic tool. Inclusion criteria and exclusion criteria for the study are listed in Table 1.

The diagnosis, according to the research criteria of ICD-10, ${ }^{63}$ was confirmed by three independent psychiatrists: an outpatient psychiatrist, who first assessed the patients, a psychiatrist at the psychotherapeutic department, and a senior psychiatrist, who supervised the department. Also, the diagnosis must be confirmed in the documentation of the patients at the end of the treatment on the last day of hospitalization.

\section{Measurements}

The patients who agreed to contribute to the study signed an informed consent form and completed several scales. The following measurements were completed at the start and end of the treatment:

1. Beck Depression Inventory, second edition (BDI-II) ${ }^{64}-$ The scale includes 21 items - depressive symptoms - in which patients choose perceived symptoms and their severity during the last week. Internal consistency of the scale is higher in psychiatric population $(\alpha=0.86)$ than in general population $(\alpha=0.81) .{ }^{64}$ Preiss and $\operatorname{Vacir}^{65}$ published the Czech version.

2. Clinical Global Impression (CGI) - The scale is used for the global assessment of the severity of psychopathology. ${ }^{66}$ In this study, the subjective evaluation of CGI

Table I Inclusion and exclusion criteria

Inclusion criteria
I. Depressive disorder, panic disorder, generalized anxiety disorder,
mixed anxiety-depressive disorder, agoraphobia, social phobia, OCD,
PTSD, adjustment disorders, dissociative/conversion disorders,
somatoform disorder, or other anxiety/neurotic spectrum disorder
(WHO 1996)
2. Both sexes
3. Age between I8 and 70 years
4. Informed consent
Exclusion criteria
I. Severe somatic illness
2. Organic psychiatric disorder
3. Bipolar affective disorder lifetime
4. Alcohol or substance dependency
5. Schizophrenia lifetime
6. Mental retardation
7. Acute suicidal behavior or plan
8. Patients using no prescribed medication
9. Dissocial personality disorder

Abbreviations: $O C D$, obsessive compulsive disorder; PTSD, posttraumatic stress disorder; WHO, World Health Organization. severity was used. The scale measures the severity of the disorder (CGI-S) and also improvement during the therapy (CGI-I). The patient assesses himself/herself by the subjective version of the scale, which includes seven levels of severity of the psychopathology or level of improvement during the therapy. Internal consistency of the scale seems to be satisfactory. ${ }^{67}$

3. Beck Anxiety Scale (BAI) - The scale consists of 21 items - anxiety symptoms - scored on a four-point Likert scale. ${ }^{68}$ The patients choose perceived symptoms and their severity during the last week. The method has excellent internal consistency (mean $\alpha=0.91) .{ }^{69}$ The validation of the Czech translation is currently in progress. Its Cronbach alpha is $0.92 .^{70}$

4. Sheehan Patient-Related Anxiety Scale (SPRAS) - The scale was designed to provide an overview measure of the severity of anxiety symptoms. ${ }^{71,72}$ It consists of 35 items describing the anxiety symptoms, scored on a four-point Likert scale. They elicit the individual symptoms that occur during or as a direct consequence of anxiety states, and they reflect improvement in the overall condition in response to treatment. Patients assess their state during the previous week. Ratings above 30 are usually considered abnormal, and scores above 80 are severe. The English version of the scale has excellent validity, with a specificity of $94 \%$ and a positive predictive value of $75 \%{ }^{73}$ The translated version of the scale has been used for therapeutic reasons in the Czech Republic for $>20$ years, but the validation of the Czech translation has not been performed yet.

5. Dissociative Experience Scale (DES) - The method describes 28 dissociative experiences, and patients mark a spot on a $10 \mathrm{~cm}$ line according to the frequency of experiencing the symptoms. ${ }^{74}$ Current modifications of the dissociation model have arrived at the difference between a dimensional, nonpathological type and a discontinuous, pathological class of dissociation, which can be recognized by a subgroup of eight items of the DES, the DES-Taxon (DES-T). ${ }^{75}$ This subscale consists of 8 out of the 28 DES items (items 3, 5, 7, 8, 12, 13, 22, and 27). ${ }^{76}$ The Czech version of the scale is similar to the original version regarding its validity, test-retest reliability, and the factor structure. ${ }^{77}$

The following measurement was completed only at the beginning of the treatment:

Demographic questionnaire contained basic information such as sex, age, age at disease onset, number of hospitalizations, employment status, education, pension status, duration 
of attendance at the outpatient clinic, time since the last hospitalization, current medication, number of psychiatrists visited, and discontinuation of drugs in the past (recommended by a psychiatrist or arbitrarily).

The primary outcome criteria were defined as

1. relative change during the therapy in BDI-II and BAI (the difference between rating at the beginning and rating at the end of the therapy divided by the beginning score);

2. absolute change in CGI-S ratings (the difference between rating at the start and rating at the end);

3. the treatment response was considered as a decrease of $30 \%$ or more in BDI-II in depression symptomatology and $30 \%$ in BAI in anxiety symptomatology;

4. minimal improvement showed a decrease of one point in the severity of CGI-S and moderate improvement showed a reduction of two points in CGI-S; and

5. remission was defined as a score one or two in the last measurement of CGI-S.

\section{Methods of the treatment}

All patients were hospitalized for 6 weeks in the psychotherapeutic department of the Department of Psychiatry, University Hospital Olomouc. Psychotherapy was provided in two different groups: CBT or brief psychodynamic therapy, both in combination with pharmacotherapy. The patients used antidepressants, mainly selective serotonin reuptake inhibitors, with a mean daily dosage of $41.26 \pm 24.10 \mathrm{mg}$ of the paroxetine index $(n=502)$, a mean daily dosage of anxiolytics $17.63 \pm 18.09 \mathrm{mg}(\mathrm{n}=231)$ of the diazepam index, and a mean daily dosage of antipsychotics $1.739 \pm 1.985 \mathrm{mg}$ $(n=212)$ of the risperidone index at the beginning or the treatment (Table 2). The change of the antidepressant and its dosage was not frequent. At the end of the treatment, the mean daily dosage of antidepressant was $41.29 \pm 23.88 \mathrm{mg}$ and the number of patients using antidepressants increased $(n=532)$. There was an effort to decrease or stop medication with anxiolytics - the number of patients treated with benzodiazepines dropped from 231 patients at the beginning of the treatment to 164 at the end, with a mean daily dosage of $15.93 \pm 15.83 \mathrm{mg}$ of the diazepam index. Also, the number of patients with adjuvant antipsychotic medication decreased during the treatment from 212 to 157 , with a final mean daily dosage of $1.602 \pm 2.055 \mathrm{mg}$ of the risperidone index. Patients attended 30 group sessions (CBT or short psychodynamic therapy) and a minimum of five individual sessions. The therapeutic group program community sessions included drama therapy, progressive muscle relaxation, art therapy, mental imagery, occupational therapy, and physical activities. There was no randomization to the type of psychotherapy.

Table 2 Demographic and clinical data - comparison of all enrolled patients and the patients who completed the study

\begin{tabular}{|c|c|c|c|}
\hline Variable & $\begin{array}{l}\text { Enrolled patients } \\
(n=840)\end{array}$ & $\begin{array}{l}\text { Patients who completed } \\
\text { the study }(n=606)\end{array}$ & $\begin{array}{l}\text { Statistics: enrolled patients versus } \\
\text { patients completing the study }\end{array}$ \\
\hline Age & $38.7 \pm 12.3$ & $38.6 \pm 12.3$ & Mann-Whitney test: MW U=246,800; ns \\
\hline $\operatorname{Sex}(M / F)$ & $278 / 562$ & $|92 / 4| 4$ & Fisher's exact test: ns \\
\hline Age at onset of the disorder & $30.3 \pm 13.9$ & $30.3 \pm 13.8$ & Mann-Whitney test: MW U $=247,000$; ns \\
\hline Duration of the disorder & $8.3 \pm 8.8$ & $8.3 \pm 8.8$ & Mann-Whitney test: $M W U=247,000$; ns \\
\hline Heredity no/yes & $438 / 402$ & $324 / 282$ & Fisher's exact test: ns \\
\hline $\begin{array}{l}\text { Education basic/vocational training/secondary } \\
\text { school/university }\end{array}$ & $1 \mid 8 / 251 / 333 / 115$ & $83 / 187 / 251 / 84$ & Chi-square test: ns \\
\hline No information & 23 & I & \\
\hline Employed/unemployed & $484 / 356$ & $244 / 362$ & Fisher's exact test: ns \\
\hline No pension/pension & $657 / 183$ & $474 / 132$ & Fisher's exact test: ns \\
\hline Marital status: single/married/divorced/widowed & $355 / 267 /|65 / 3|$ & $259 / 201 / 120 / 26$ & Chi-square test: ns \\
\hline No information & 22 & 0 & \\
\hline Personality disorder no/yes & $614 / 226$ & $442 / 164$ & Fisher's exact test: ns \\
\hline CGI-S-I & $4.1 \pm 1.7$ & $4.3 \pm 1.4$ & Mann-Whitney test: $M W U=238,700 ;$ ns \\
\hline BAl-I & $23.1 \pm 14.0$ & $24.1 \pm 12.5$ & Mann-Whitney test: $M W U=235,100$; ns \\
\hline BDI-II-I & $24.0 \pm 11.6$ & $25.0 \pm 10.4$ & Unpaired $t$-test: $t=I .585, d f=I, 40 I$; ns \\
\hline SPRAS- I & $60.1 \pm 33.6$ & $59.9 \pm 35.5$ & Mann-Whitney test: $M W U=213,500$; ns \\
\hline DES-I & $14.5 \pm 15.4$ & $14.3 \pm 15.4$ & Mann-Whitney test: $M W U=202,600 ;$ ns \\
\hline Antidepressant index & $41.26 \pm 24.10(n=502)$ & $41.29 \pm 23.88(n=532)$ & Mann-Whitney test: $M W U=202,600$; ns \\
\hline Anxiolytic index & $17.63 \pm 18.09(n=231)$ & $15.93 \pm 15.83(n=164)$ & Mann-Whitney test: $M W U=17,760$; ns \\
\hline Antipsychotic index & $1.739 \pm 1.985(n=212)$ & $1.602 \pm 2.055(n=157)$ & Mann-Whitney test: $M W U=15,560$; ns \\
\hline
\end{tabular}

Abbreviations: BAI, Beck Anxiety Inventory; BDI-II, Beck Depressive Inventory, second edition; CGI-S, Clinical Global Impression-Severity of the disorder; DES, Dissocative Experience Scale; df, degrees of freedom; F, females; M, males; ns, not significant; SPRAS, Sheehan Patient-Related Anxiety Scale. 
Patients with adjustment disorders, mixed anxiety-depressive disorder, and the patients who had historical experience with CBT were preferentially treated by short psychodynamic therapy, while the patients with phobias, OCD, and BPD were preferred in CBT program.

\section{Statistics}

Statistical analysis was performed using the statistical software Statistical Package for the Social Sciences 24.0 (IBM Corporation, Armonk, NY, USA) and the Prism (GraphPad PRISM version 5.0; http://www.graphpad.com/prism/prism. htm). The applied statistical procedures were descriptive statistics for the demographic data, mean scores, and a character of data distribution. Differences between the scores obtained at the start and end of the treatment were calculated by parametric or nonparametric paired $t$-tests. The chi-square tests were used for the categorical variables. Differences in the decline of the scores in patients with and without comorbid depression and in patients undergoing CBT or short-term psychodynamic therapy were calculated by two-way analysis of variance, followed by Bonferroni's Multiple Comparison Test. Relationships between treatment outcome and other factors were found by correlations and a multiple stepwise regression analysis. Differences were considered to be significant when the $P$-values were $<0.05$.

\section{Ethics statement}

The investigation was performed in agreement with the latest version of the Helsinki Declaration and the Guideline for Good Clinical Practice. ${ }^{78}$ The local ethical committee of University Palacky Olomouc, Faculty of Medicine and Dentistry accepted the study. Written informed consent was obtained from all participants after the procedures had been fully explained.

\section{Results}

\section{Sample description}

The research was conducted from January 2012 to July 2014. A total of 840 patients with anxiety or depressive spectrum disorders who were resistant to pharmacological treatment on an outpatient basis and were advised hospitalization for the 6-week complex therapeutic program were enrolled in this inpatient study (Table 2). Data of 606 patients were statistically analyzed. Data of 234 (27.9\%) patients were not used as 103 patients prematurely dropped out from the treatment due to various reasons ( 74 preferred shorter program, 11 finished the program due to responsibilities in their families or work, 18 were moved to another department of the hospital [7 because of somatic disease and 11 because of changing the diagnosis or fulfilling the exclusion criteria]) and 131 finished the entire therapeutic program but did not cooperate in the filling up of most questionnaires. There were no significant differences in any of the demographic or clinical characteristics between the entire enrolled group and the group that finished the program (Table 2). There were no patients with pure diagnosis of PD without comorbid anxiety and neurotic spectrum disorder or depression in this group because patients were admitted to the department primarily due to anxiety and depressive disorders. All patients with PDs had comorbidity with another axis I disorder. The reason is the type of shortterm psychotherapeutic programs which focus mostly on anxiety and depressive spectrum disorders.

The mean scores on the rating scales at the beginning of the treatment according to diagnostic groups showed significant differences in all measurements except DES-T (Table 3).

\section{Rating scales and dissociation - effect of the treatment}

Significant improvements were seen in all the primary parameters; CGI-S, BDI-II, BAI, and SPRAS total scores improved from baseline to the end of the treatment (Table 4; Figure 1). The mean ratings of DES and DES-T did not change significantly (Table 4).

Treatment response in depressive symptomatology, defined as an improvement by $>30 \%$ of the initial BDI-II score, was shown by $45.7 \%$ of the patients. Treatment response in anxiety symptomatology, defined as an improvement by $>30 \%$ of the BAI score, was found in $39.5 \%$ of the patients. Minimal improvement according to CGI-S (change of minimum one point) was shown by $67.5 \%$ of all patients, and moderate (CGI-S change of two points) and higher improvement was shown by $42.4 \%$ of all patients. Remission, defined as the last CGI-S score of 1 or 2, was achieved by $35.3 \%$ of the patients.

\section{Rating scales before and after treatment according to the demographic and clinical data}

Comparison of scores on BDI-II, BAI, CGI-S, and SPRAS before and after treatment did not show differences between the subgroups divided according to sex, employment, marital status, partnership, heredity, and type of psychotherapy (Table 5). 


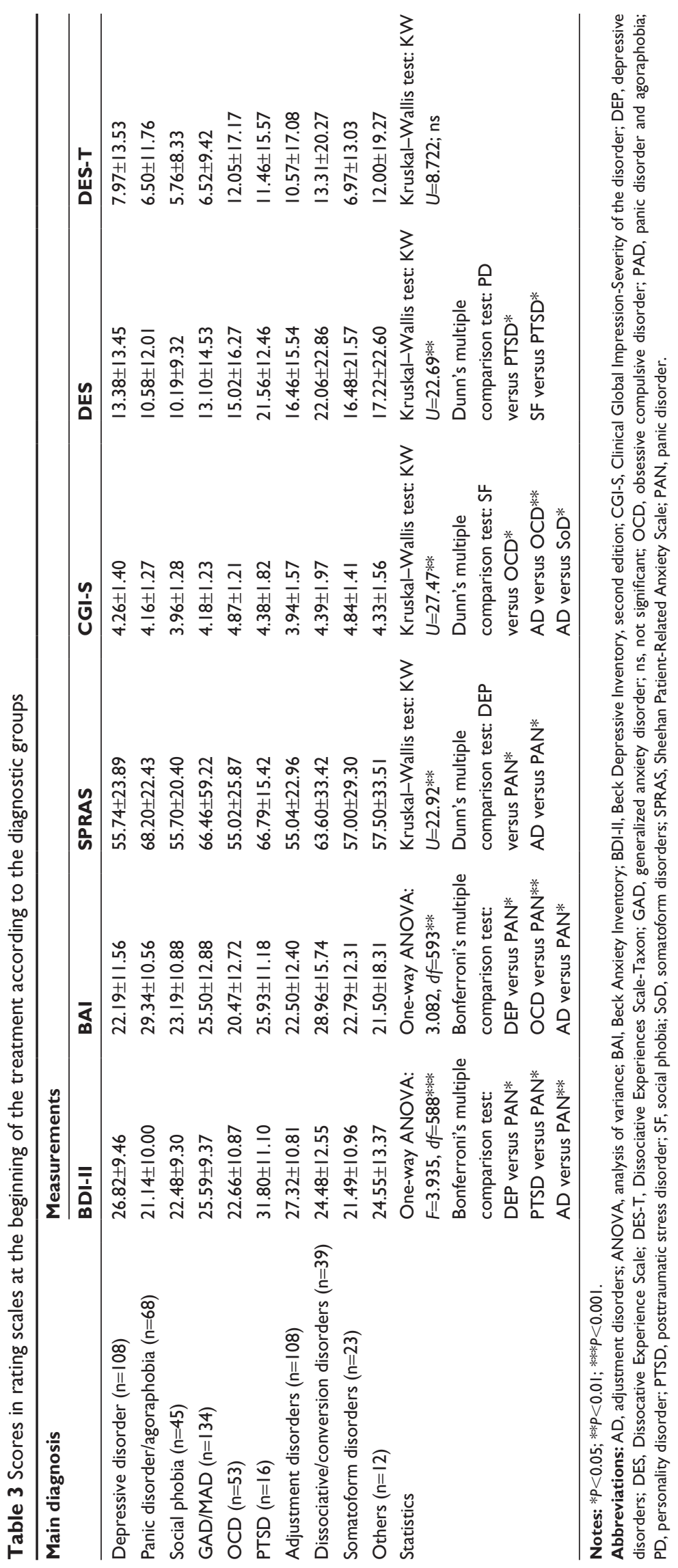




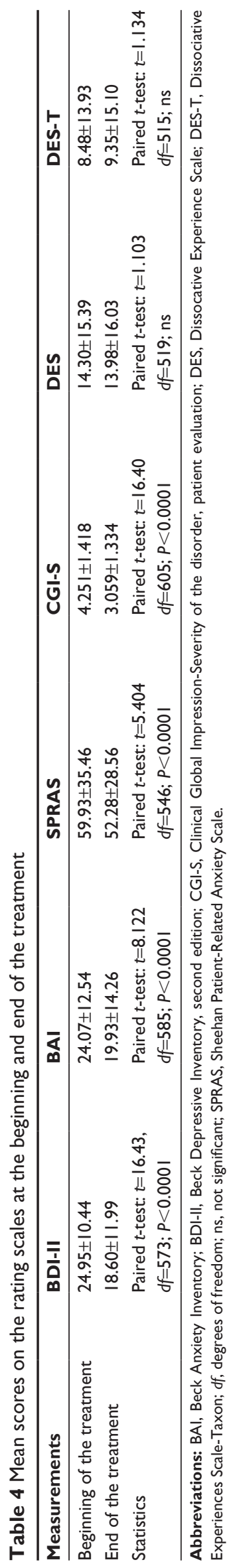

\section{Rating scales and dissociation before and after treatment according to the diagnostic groups}

Comparison of the changes in scores during the therapy among the diagnostic groups was made in all outcome measures (BDI-II relative change, BAI relative change, and CGI-S absolute change) and SPRAS relative change and DES relative change. There were statistically significant differences in the relative changes in the depressive scores in BDI-II and the anxiety scores in BAI among the diagnostic groups (Table 6). The post-hoc analysis of BDI-II using Dunn's multiple comparison tests showed, that changes were found among the group of patients with panic disorder and agoraphobia versus OCD and versus dissociative disorders groups. There were significant differences in BAI relative changes on comparing panic disorder/agoraphobia and adjustment disorder groups. No significant changes were found among the diagnostic groups in the CGI-S absolute change, SPRAS relative change, and DES relative change; that is, there were no significant differences among the diagnostic groups in the mean change of the level of dissociation during the treatment (Table 6).

\section{Relative change during the therapy according to the demographic and clinical data}

Taking into account the relative change in BDI-II and BAI and the absolute change in CGI-S as a main outcome criterion for improvement, these changes did not correlate significantly with demographic factors such as age, onset of beginning of depression, duration of the disorder, or dosages of medication, with two exceptions, that is, duration of the disorder and dosage of antidepressants that correlated positively with the CGI-S absolute change but not with other outcome measures (Table 7).

BDI-II relative change statistically significantly correlated negatively with all measurements (BDI-II, BAI, CGI-S, SPRAS, DES, and DES-T) at the start of the treatment and positively with the relative DES and relative DES-T changes (Table 6). The depressive symptomatology improved significantly more in patients who had lower psychopathology at the start of the treatment. Higher relative change in the depressive symptoms was positively correlated with higher relative change in dissociation symptoms in our sample.

The BAI relative change significantly negatively correlated with the level of the depressive symptoms in BDI-II, the anxiety symptoms in SPRAS, and the degree of dissociation in DES and DES-T, positively correlated with the anxiety symptoms in BAI, and highly positively correlated 
A

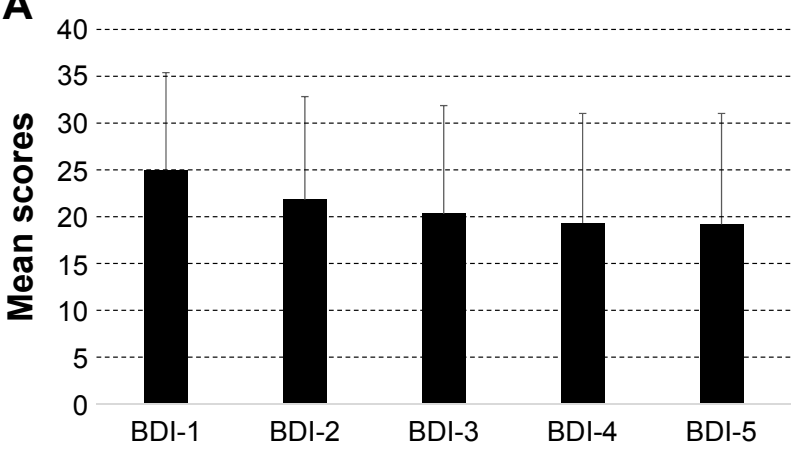

B

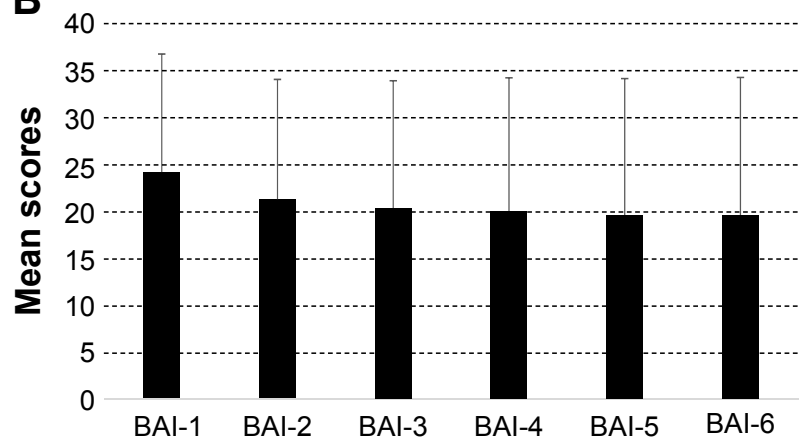

Figure I Mean BDI-II and BAI scores each week during the treatment.

Notes: (A) Statistics: Kruskal-Wallis test, $P<0.000$ I; Dunn's multiple comparison test: $B D I-I$ versus $B D I-2, P<0.00 I$; $B D I-2$ versus $B D I-3, P<0.00 I$; $B D I-3$ versus $B D I-4$, $P<0.00$ I; $B D I-4$ versus BDI-5, ns; $B D I-5$ versus BDI-6, $P<0.00$ I. (B) Statistics: Kruskal-Wallis test, $P<0.000$ I; Dunn's multiple comparison test: $B A I-I$ versus $B A I-2, P<0.00 I$; $\mathrm{BAI}-2$ versus $\mathrm{BAI}-3, P<0.00$ I; $\mathrm{BAl}-3$ versus $\mathrm{BAI}-4, P<0.00$ I; $\mathrm{BAl}-4$ versus $\mathrm{BAI}-5, P<0.00$ I; $\mathrm{BAl}-5$ versus $\mathrm{BAI}-6, P<0.00 \mathrm{I}$.

Abbreviations: BAI, Beck Anxiety Inventory; BDI, Beck Depressive Inventory, second edition; ns, not significant.

with the DES relative change during the therapy and the DES-T change.

The CGI-S absolute change highly significantly positively correlated with the duration of the disorder, the severity of the disorder at the beginning of the treatment (CGI-S-1), the level of anxiety at the beginning measured by BAI and SPRAS, the level of depression measured by BDI-II, and the dosage of an antidepressant. However, the CGI-S absolute change did not correlate with the degree of the dissociation (DES-1) or the pathological dissociation (DES-T-1) at the beginning of the study. Nevertheless, it correlated positively with the DES relative change and the DES-T relative change. It means that changes in the severity of the disorder correlated with reduction of dissociation.

\section{Personality disorders}

A PD was diagnosed in 164 patients (27.1\%). Statistically significant differences were detected in some demographic factors between the patients with and without comorbidity of PD at the beginning of the study. The patients with a comorbid PD were significantly younger than the patients without a PD. At the beginning of the treatment, the differences between the subgroups were also significant in the age of onset of the disorder, severity of depressive symptoms measured by BDI-II, and severity of anxiety symptoms measured by BAI, but not in the severity of the disorder assessed by CGI-S or the amount of anxiety symptoms measured by SPRAS (Table 8). No significant differences were found in the dosage of medication between the groups with and without PDs (Table 8).

Patients with comorbid PD significantly differed in the reduction of the depression level measured by the BDI-II relative change (Table 8). However, there were no statistically significant differences in most of the other parameters, such as duration of the disorder, the BAI relative change, the CGI-S absolute change, the SPRAS relative change, the DES relative change, and the DES-T relative change (Table 8).

\section{Multiple regression analyses}

As various factors are significantly related to the main outcome criteria, multiple regression analyses (backward stepwise regression) were performed to identify the most important factors linked to BDI-II relative change, BAI relative change, and CGI-S absolute change as the dependent variable.

\section{Relative BDI-II change}

The independent variables that entered the regression analysis were patient's diagnosis, comorbidity with a PD, comorbidity with somatic illness, BDI-II-1, BAI-1, SPRAS-1, DES-1, DES-T-1, relative DES change, and relative DES-T change. Backward stepwise regression consisted of eight steps during which most of the independent variables previously correlated with the BDI-II relative change were removed. Only four regressors sustained (Table 9).

The strongest factors that were negatively correlated to the BDI-II relative change were a comorbid PD, the BAI score at the beginning of the program, and pathological dissociation measured by DES-T. The BDI-II relative change strongly positively correlated with the relative DES-T change.

\section{Relative BAI change}

The BAI relative change as a dependent factor was analyzed in connection with patient's diagnosis, marital status, somatic comorbidity, BAI-1, BDI-1, SPRAS-1, DES-1, DES-T-1, relative DES change, and relative DES-T change. Backward stepwise regression consisted of seven steps during which 


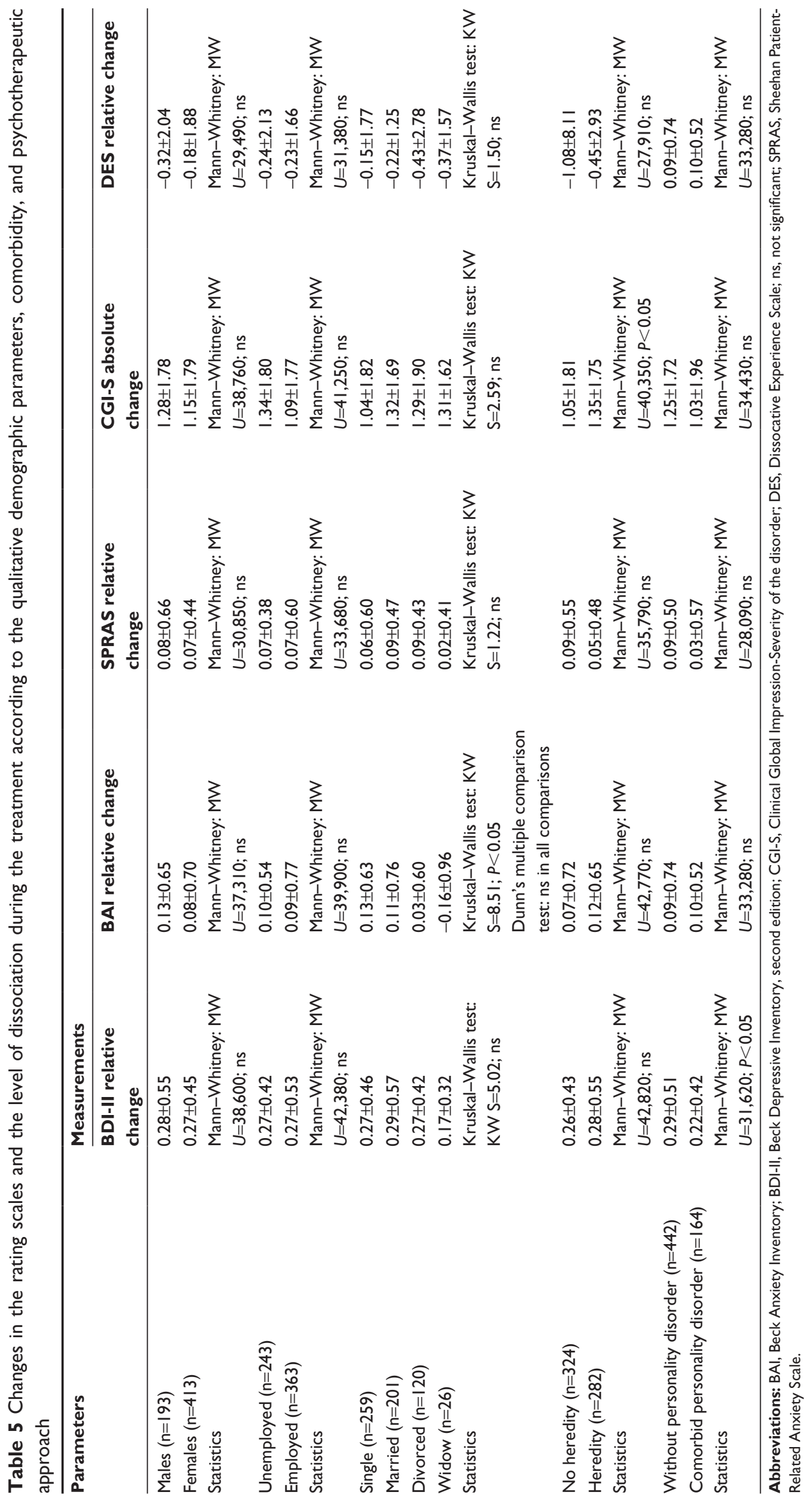




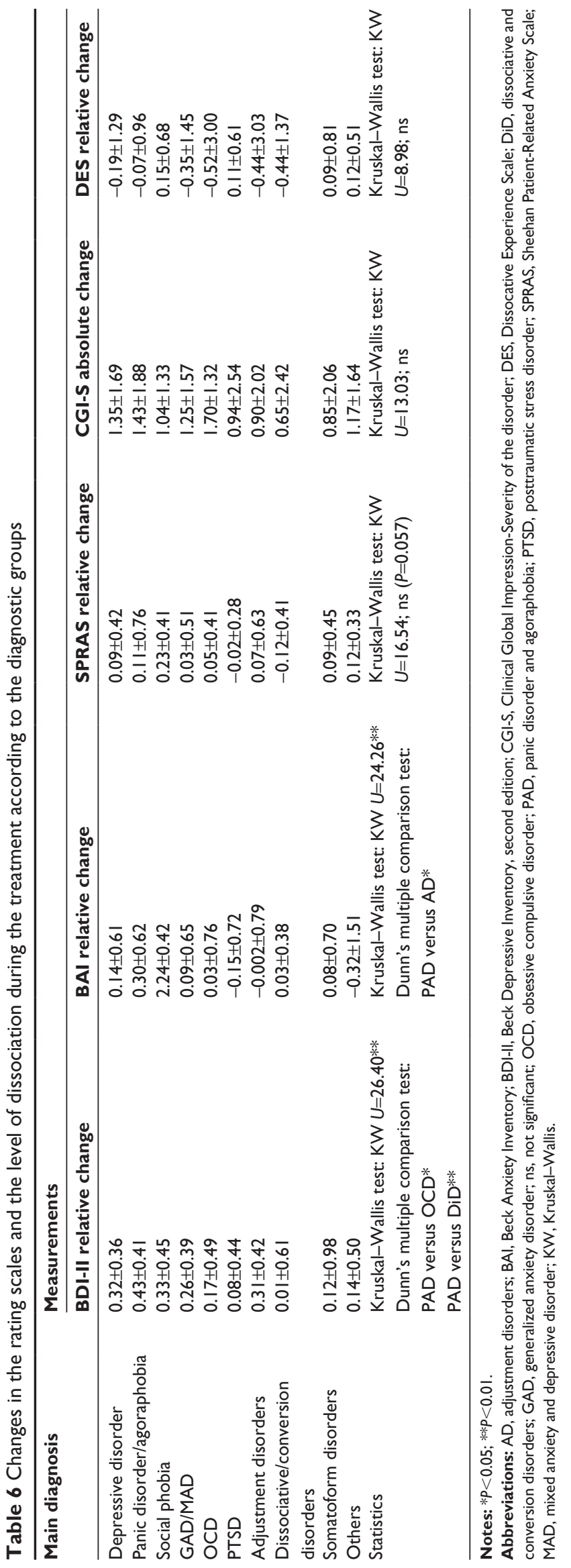

Table 7 Correlations of the relative change in BDI-II and BAI and the absolute change in CGI-S with demographic and clinical data

\begin{tabular}{llll}
\hline Measurement & \multicolumn{2}{l}{ Outcome criteria } \\
\cline { 2 - 4 } & $\begin{array}{l}\text { BDI-II } \\
\text { relative } \\
\text { change }\end{array}$ & $\begin{array}{l}\text { BAI } \\
\text { relative } \\
\text { change }\end{array}$ & $\begin{array}{l}\text { CGI-S } \\
\text { absolute } \\
\text { change }\end{array}$ \\
\hline Age & -0.04 & -0.07 & 0.03 \\
Onset of the disorder & -0.04 & -0.07 & -0.02 \\
Duration of the disorder & -0.03 & -0.01 & $0.09 S^{* *}$ \\
BDI-II-I & $-0.08 S^{*}$ & $-0.11 S^{* *}$ & $0.09 S^{* *}$ \\
BAI-I & $-0.1 S^{* *}$ & $0.11 S^{* *}$ & $0.13 S^{* *}$ \\
CGI-S-I & $-0.13 S^{* *}$ & -0.04 & $0.70 S^{* * *}$ \\
SPRAS-I & $-0.17 S^{* * *}$ & $-0.11 S^{* *}$ & $0.16 S^{* * *}$ \\
DES-I & $-0.19 S^{* * *}$ & $-0.15 S^{* * *}$ & $-0.0 I$ \\
DES-T-I & $-0.18 S^{* * *}$ & $-0.12 S^{* *}$ & -0.003 \\
Relative DES change & $0.27 S^{* * *}$ & $0.22 S^{* * *}$ & $0.15 S^{* * *}$ \\
Relative DES-T change & $0.18 S^{* * *}$ & $0.14 S^{* *}$ & $0.10 S^{*}$ \\
Antidepressant paroxetine index & -0.04 & 0.01 & $0.10 S^{*}$ \\
Anxiolytic diazepam index & 0.004 & 0.02 & 0.08 \\
Antipsychotic risperidon index & -0.07 & -0.04 & 0.12 \\
\hline
\end{tabular}

Notes: S, Spearman $r$. $* P<0.05 ; * * P<0.01 ; * * * P<0.001$.

Abbreviations: BAI, Beck Anxiety Inventory; BDI-II, Beck Depressive Inventory, second edition; CGI-S, Clinical Global Impression-Severity of the disorder; DES, Dissocative Experience Scale; DES-T, Dissociative Experiences Scale-Taxon; SPRAS, Sheehan Patient-Related Anxiety Scale.

most of the entered variables, except BDI-II and BAI, measured at the beginning of the program were removed, but only BAI achieved significance. Other variables which sustained were pathological dissociation measured by DES-T that correlated significantly negatively with the dependent variable and the DES relative change that correlated positively (Table 10).

\section{Absolute CGI-S change}

The CGI-S absolute change as a dependent variable in regression was analyzed in connection with the duration of the disorder, heredity in the family, the scores of CGI-S, BDI-II, BAI, and SPRS at the beginning of the treatment, relative DES change, and the relative DES-T change. During nine steps, most of the variables were removed. Only three variables remained. The strongest factors connected to the CGI-S absolute change were CGI-S at the beginning that correlated positively and BDI-II at the beginning that correlated negatively. The CGI-S absolute change also correlated significantly positively with the DES-T change during the treatment (Table 11).

\section{Remission}

Variables entered in Step 1 were: comorbidity with a PD, diagnosis, psychiatric comorbidity, comorbidity with somatic illness, age, onset, duration, occupation, marital status, 
Table 8 Comparison of the patients with and without comorbid personality disorder

\begin{tabular}{|c|c|c|c|}
\hline Variable & $\begin{array}{l}\text { Without personality } \\
\text { disorder }(n=442)\end{array}$ & $\begin{array}{l}\text { With personality } \\
\text { disorder }(n=164)\end{array}$ & Statistics \\
\hline Age & $40.63 \pm 12.38$ & $33.13 \pm 10.07$ & Mann-Whitney test: $M W U=23,460 ; P<0.000 I$ \\
\hline Age at onset of the disorder & $32.22 \pm 14.00$ & $25.05 \pm 11.60$ & Mann-Whitney test: $M W U=25,270 ; P<0.000 I$ \\
\hline Duration of the disorder & $8.42 \pm 9.21$ & $7.82 \pm 7.47$ & Mann-Whitney: MW U=35,600; ns \\
\hline BDI-II-I & $23.68 \pm 10.07$ & $28.36 \pm 10.69$ & Mann-Whitney: MW U=25,640; $P<0.000$ I \\
\hline BAI-I & $23.32 \pm 12.55$ & $26.07 \pm|2.3|$ & Mann-Whitney: MW U=30,420; $P<0.05$ \\
\hline SPRAS-I & $59.12 \pm 39.16$ & $61.74 \pm 23.45$ & Mann-Whitney: $M W U=29,180 ;$ ns $(P=0.06)$ \\
\hline CGI-S-I & $4.258 \pm 1.418$ & $4.232 \pm 1.421$ & Mann-Whitney: MW U=35,940; ns \\
\hline DES-I & $13.01 \pm 15.55$ & $|7.52 \pm| 4.5 \mid$ & Mann-Whitney: MW U=20,720; $P<0.000$ I \\
\hline DES-T-I & $7.115 \pm 12.71$ & $11.91 \pm 16.14$ & Mann-Whitney: MW U=24, I00; $P<0.000 \mathrm{I}$ \\
\hline Antidepressant index & $40.52 \pm 23.54(n=374)$ & $42.65 \pm 24.28(n=128)$ & Mann-Whitney: MW U=22,750; ns \\
\hline Anxiolytic index & $15.75 \pm 15.87(n=100)$ & $16.36 \pm 15.90(n=49)$ & Mann-Whitney: MW U=2,73I; ns \\
\hline Antipsychotic index & $1.577 \pm 2.248(n=107)$ & $1.655 \pm 1.585(\mathrm{n}=50)$ & Mann-Whitney: MW U=2,482; ns \\
\hline $\mathrm{BDI}-\mathrm{Il}$ relative change & $0.29 \pm 0.5 \mathrm{I}$ & $0.22 \pm 0.42$ & Mann-Whitney: MW $U=31,620, P<0.05$ \\
\hline $\mathrm{BAI}$ relative change & $0.09 \pm 0.74$ & $0.10 \pm 0.52$ & Mann-Whitney: MW U=33,280; ns \\
\hline SPRAS relative change & $0.09 \pm 0.50$ & $0.03 \pm 0.57$ & Mann-Whitney: MW U=28,090; ns \\
\hline CGI-S absolute change & $1.25 \pm 1.72$ & $1.03 \pm 1.96$ & Mann-Whitney: MW U=33,280; ns \\
\hline DES relative change & $-0.1757 \pm 1.609$ & $-0.3764 \pm 2.349$ & Mann-Whitney: MW U=24,630; ns \\
\hline DES-T relative change & $-0.7948 \pm 7.088$ & $-0.7461 \pm 3.552$ & Mann-Whitney: MW U=21,910; ns \\
\hline
\end{tabular}

Abbreviations: BAI, Beck Anxiety Inventory; BDI-II, Beck Depressive Inventory, second edition; CGI-S, Clinical Global Impression-Severity of the disorder; DES, Dissocative Experience Scale; DES-T, Dissociative Experiences Scale-Taxon; ns, not significant; SPRAS, Sheehan Patient-Related Anxiety Scale.

education, heredity, antidepressant index, BAI-1, BDI-II-1, CGI-S-1, SPRAS-1, DES-1, DES-T-1, the relative DES change, and the relative DES-T change. After the 16th step, the logistic regression finished with the model, in which the diagnoses (especially social phobia, OCD, PTSD, and somatoform disorder), the degree of dissociation and pathological dissociation, and severity of the depressive symptoms at the beginning of the treatment were evaluated as the strongest negative predictors of achieving remission during the treatment program (Table 12).

\section{Discussion}

In the present study, the average levels of anxiety, depression, and severity of the disorder are in accordance with other inpatients studies of such populations, and also with the results of our study with inpatients suffering from anxiety

Table 9 Backward stepwise regression with BDI-II relative change as the dependent variable

\begin{tabular}{lllllll}
\hline Model & Regressors & B & SE & $\boldsymbol{\beta}$ & $\boldsymbol{t}$ & Significance \\
\hline 8 & Comorbid PD & -0.122 & 0.047 & -0.128 & -2.610 & 0.009 \\
& BAI-I & -0.003 & 0.002 & -0.091 & -1.745 & 0.082 \\
& DES-T-I & -0.006 & 0.002 & -0.182 & -3.463 & 0.001 \\
& Relative & 0.027 & 0.008 & 0.159 & 3.277 & 0.001 \\
& DES-T change & & & & & \\
\hline
\end{tabular}

Notes: ANOVA: $F=10.33, d f=391 ; P<0.000$. Adjusted $r^{2}=0.087$.

Abbreviations: ANOVA, analysis of variance; BAI, Beck Anxiety Inventory; BDI-II, Beck Depressive Inventory, second edition; DES-T, Dissociative Experiences ScaleTaxon; PD, personality disorder; SE, standard error. disorders in the period 2009-2010. ${ }^{79}$ The first hypothesis, that is, "during the therapeutic process, there would be improvement in the degree of depression, anxiety, and the severity of the disorder", was confirmed in all outcome criteria and all diagnostic groups. The patients' mean ratings on all scales were reduced during the treatment. Also, $67.5 \%$ of the patients reached minimal and higher improvement, $42.4 \%$ of them attained moderate and more improvement, and remission was achieved in $35.3 \%$ of the patients. The improvement and remission rate are encouraging in the light of the fact that these patients had been resistant to the previous outpatient pharmacological treatment. There are some studies reporting similar results in patients with resistant depression. ${ }^{80,81}$ Also, in the study of Wiles et $a 1,{ }^{82}$ in patients who had not responded to antidepressants, augmentation with CBT was effective in decreasing the depressive symptoms, and these

Table 10 Backward stepwise regression with the BAI relative change as the dependent variable

\begin{tabular}{lllllll}
\hline Model & Regressors & B & SE & $\boldsymbol{\beta}$ & $\boldsymbol{t}$ & Significance \\
\hline 7 & BAI-I & 0.017 & 0.003 & 0.308 & 5.540 & 0.000 \\
& BDI-II-I & -0.007 & 0.004 & -0.104 & -1.872 & 0.062 \\
& DES-T-I & -0.009 & 0.002 & -0.192 & -3.718 & 0.000 \\
& Relative & 0.046 & 0.016 & 0.134 & 2.819 & 0.005 \\
& DES change & & & & & \\
\hline
\end{tabular}

Notes: ANOVA: $F=11.26, d f=407 ; P<0.000$. Adjusted $r^{2}=0.092$.

Abbreviations: ANOVA, analysis of variance; BAI, Beck Anxiety Inventory; BDI-II, Beck Depressive Inventory, second edition; DES, Dissocative Experience Scale; DES-T, Dissociative Experiences Scale-Taxon; df, degrees of freedom; SE, standard error. 
Table II Backward stepwise regression with CGI-S absolute change as the dependent variable

\begin{tabular}{lllllll}
\hline Model & Regressors & B & SE & $\boldsymbol{\beta}$ & $\boldsymbol{t}$ & Significance \\
\hline 9 & CGI-S-I & 0.889 & 0.054 & 0.696 & $16.46 \mathrm{I}$ & 0.000 \\
& BDI-II-I & -0.023 & 0.007 & -0.133 & $-3.17 \mathrm{I}$ & 0.002 \\
& Relative & 0.052 & 0.022 & 0.093 & 2.326 & 0.021 \\
& DES-T change & & & & & \\
\hline
\end{tabular}

Notes: ANOVA: $F=97.34, d f=341 ; P<0.000$. Adjusted $r^{2}=0.459$.

Abbreviations: ANOVA, analysis of variance; BDI-II, Beck Depressive Inventory, second edition; CGI-S, Clinical Global Impression-Severity of the disorder; DES-T, Dissociative Experiences Scale-Taxon; df, degrees of freedom; SE, standard error.

effects, including the outcomes reflecting remission, were maintained over 12 months.

The second hypothesis was "the responses to the treatment would be different according to the marital status, heredity, and employment status". There were no differences in the treatment response in any of the outcome criteria according to the employment status. These findings are in contrast with the study of van der Lem et al, ${ }^{83}$ who showed that being employed contributed to a positive treatment outcome in major depressive disorder in daily practice. Also, the STAR*D trial demonstrated that socioeconomic data such as low income, education, and unemployment were most discriminative in predicting a poor response to citalopram in depressive outpatients. ${ }^{84}$ The different results could be attributed to the diverse patient population. The majority of our group consisted of patients with various types of anxiety disorders and all patients were resistant to the earlier outpatient treatment, which is not true for the patients described in the referred study. In future studies, it is important to focus more deeply on the job; in many patients, employment can be connected with high level of frustration or stress. In the study of Quilty et al, ${ }^{85}$ pretreatment rigidity and agentic problems predicted less reduction in depressive symptoms, whereas agentic and communal impact upon therapists during treatment predicted greater change in symptoms.

However, there was a statistically significant difference in the change of severity of the disorder assessed by CGI-S between the patients with and without heredity, but not in other outcome criteria. It remains unclear whether a positive family history of depression or anxiety disorder affects the effectiveness of treatment for major depressive or anxiety/neurotic spectrum disorders. Husain et al ${ }^{86}$ aimed to determine whether depressed patients with a positive family history of depression differed from those without in the treatment outcome with citalopram in the STAR*D study. Over half of 2,876 participants reported a family history of a depressive disorder. A positive family history of depression was linked to an earlier age at onset of major depression, a longer length of the illness, and more frequent comorbid generalized anxiety disorder and earlier suicide attempts. These patients had a slightly faster onset of remission and slightly greater side effect burden, but they did not differ overall in response or remission rates. There was an outpatient population of depressed patients without anxiety/ neurotic spectrum disorders in the discussed study. Knorr ${ }^{87}$ studied the influence of the family history on the effect of selective serotonin reuptake inhibitors in healthy first relatives of patients with major depressive disorder and did not

Table I 2 Logistic regression - predictors for achieving remission (CGI-S last I or 2)

\begin{tabular}{|c|c|c|c|c|c|c|c|}
\hline \multicolumn{8}{|c|}{ Variables in the equation } \\
\hline Step & Variable & B & SE & Wald & $d f$ & Significance & $\operatorname{Exp}(B)$ \\
\hline \multirow[t]{14}{*}{16} & Diagnosis & & & 19.396 & 9 & 0.022 & \\
\hline & Depression & -1.426 & 0.912 & 2.443 & 1 & 0.118 & 0.240 \\
\hline & Panic/agoraphobia & $-1.24 \mid$ & 0.940 & 1.742 & I & 0.187 & 0.289 \\
\hline & Social phobia & -1.993 & 0.983 & 4.107 & I & 0.043 & 0.136 \\
\hline & GAD/MAD & -1.782 & 0.913 & 3.806 & 1 & 0.051 & 0.168 \\
\hline & OCD & -2.226 & 0.969 & 5.280 & 1 & 0.022 & 0.108 \\
\hline & PTSD & -3.079 & 1.379 & 4.984 & 1 & 0.026 & 0.046 \\
\hline & Adjustment disorders & -1.169 & 0.933 & 1.569 & 1 & 0.210 & 0.311 \\
\hline & Dissociative/conversion disorders & -2.043 & 1.138 & 3.220 & 1 & 0.073 & 0.130 \\
\hline & Somatoform disorders & -3.509 & 1.150 & 9.313 & 1 & 0.002 & 0.030 \\
\hline & Occupation & -0.397 & 0.262 & 2.301 & 1 & 0.129 & 0.672 \\
\hline & DES-I & -0.031 & 0.016 & 3.836 & 1 & 0.050 & 1.032 \\
\hline & DES-T-I & -0.066 & 0.020 & 10.302 & 1 & 0.001 & 0.936 \\
\hline & BDI-II-I & -0.039 & 0.014 & 8.070 & I & 0.005 & 0.962 \\
\hline
\end{tabular}

Notes: Chi-square test: $P<0.000$. Nagelkerke's $R^{2}=0.207$.

Abbreviations: BDI-II, Beck Depressive Inventory, second edition; CGI-S, Clinical Global Impression-Severity of the disorder; DES, Dissocative Experience Scale; DES-T, Dissociative Experiences Scale-Taxon; df, degrees of freedom; GAD, generalized anxiety disorder; OCD, obsessive compulsive disorder; PTSD, posttraumatic stress disorder; SE, standard error. 
find any difference between escitalopram and placebo on self-reported neuroticism.

There were no differences in the treatment response shown by a decrease in depressive symptoms and global clinical severity of the disorder according to the marital status, but there were statistically significant differences in decrease of anxiety symptoms measured by BAI according to the marital status. This result is interesting because most of our patients suffered with moderate to high level of anxiety symptoms at the beginning of the treatment and received a diagnosis of anxiety spectrum disorders. These findings are partly in agreement with De Carlo et al's ${ }^{88}$ study evaluating the predictors of nonresponse in major depressive disorder patients with their review of 51 papers. Some severity indicators, such as age, longer duration of the depressive episode, a higher number of hospitalizations, and a higher dosage of antidepressants, are dissimilar to our results, but the comorbidity of anxiety, severity of the illness, marital status, as well as comorbid PDs were similar to the outcome in our study and were associated with nonresponse as well as age. Our study did not search for the possible problem connected to marital status. Pitman and Hilsenroth $^{89}$ described interpersonal subtypes in patients with anxiety disorder and examined whether these subtypes are characterized by different types of pathology and respond differently to treatment. These subtypes did not differ in the severity of anxiety and the global levels of symptoms at pretreatment, but they were significantly different regarding overall interpersonal problems. Such differentiation could help in better understanding the impact of marital issues on treatment outcome.

The third hypothesis was "patients with different diagnoses will receive a response to the therapy differently". Our data did confirm this hypothesis with the findings in which the diagnostic subgroups differed statistically significantly in relative change or depressive scores measured by BDI-II relative change: the responses of patients with panic disorder and agoraphobia were significantly greater than those of patients in OCD or dissociative/conversion diagnostic groups. There were no differences in responses to the therapy in BDI-II relative change among other diagnostic groups. This result is surprising because patients with panic disorder had the lowest level of depressive symptomatology at the beginning of the treatment, and therefore, there was not much space for improvement. When looking for the other main outcome criterion - the relative change in the BAI scores - there were statistically significant differences among the diagnostic groups. Kruskal-Wallis test showed this difference in the comparison involving a group of patients with panic disorder and agoraphobia and a group of individuals with adjustment disorder, but not in comparison to other diagnostic groups. It seems that the therapeutic program for patients with panic disorder and agoraphobia was most efficacious in decreasing the depression and anxiety scores. However, there were no differences in the CGI-S absolute change among the diagnostic groups.

The fourth hypothesis was "patients without comorbid PD will improve more than patients with comorbid PD". The comorbidity with PD appeared to be an aspect contributing to the treatment efficacy in the relative BDI-II score change during the study. The patients without comorbid PD showed statistically significantly better improvement in the reduction of depressive symptoms than the patients with comorbid PD. Our study confirmed that patients without PD did not show better overall results than the patients with a PD, perhaps the relative change in depression symptomatology was higher. Comparison of the efficacy between patients with and without PDs showed that this reduction in depressive symptoms did not influence the reduction in overall severity of the disorder. The difference was not found on comparing the changes in anxiety symptoms measured by the BAI change, or severity of the disorder as measured by CGI-S. This study also showed that individuals with a comorbid PD substantially improved during the treatment, and the relative changes in anxiety symptoms and severity of the disorders were comparable between the groups with and without personality comorbidity. The outcomes are in agreement with an earlier study published by Ociskova et $\mathrm{a}^{28}$ on patients with various anxiety disorders. There are several studies that reported worse treatment results in patients with depressive disorders comorbid with PDs. ${ }^{57,90,91}$ Also, several studies reported worse treatment results in patients with anxiety disorders, OCD, or PTSD comorbid with PDs. ${ }^{88,92-94}$ Differences in the results of these studies can be explained by the different patient populations studied.

The fifth major hypothesis was "higher levels of dissociation at the beginning of the treatment predict minor improvement during therapy in the degree of depression, anxiety, and severity of the disorder". The hypothesis was confirmed with two outcome criteria measured by the level of depression (the BDI-II relative change) and anxiety (the BAI relative change), but not with the modification of the severity of the disorder (the CGI-S absolute change). These findings are equivocal and show that changes in concrete symptoms cannot reflect the subjective meaning of the overall severity of the disorder. It is also consistent with the previous findings, ${ }^{95,96}$ and with the previous results of our group in studies with less number of participants examining the 
relationship between treatment effectiveness and the level of dissociation in depressed and anxious patients and with the results of our studies in patients with $O C D$, panic disorder, and mixed neurotic spectrum and depressive disorder. ${ }^{27,28,62}$

The last of the main hypotheses was "the major therapeutic change is connected to greater reduction of dissociation". This assumption was significantly confirmed in all primary outcome criteria of our study. This result is probably the most significant finding of the present study as it is related to its main goals. Lower treatment efficacy in reduction of anxiety and depression symptoms was associated with higher rates of dissociation at the beginning of the treatment, and reduction of dissociation during the treatment correlated with decrease in severity of the disorder and also with reduction of symptoms of depression and anxiety. This result could pave way for developing innovative treatment strategies for resistant patients with anxiety or depressive symptomatology in future.

\section{Limitations of the study}

Our study has several limitations. The main one is the unavailability of full data in some patients. Another limitation is the difference in pharmacotherapy in individual patients.

Another limitation is that we used mostly the information from self-evaluation of the patients. Some patients did not fill in the questionnaires completely, so they had to be excluded from some analyses. The use of these scales and inventories depends on the ability of introspection of the probands and their willingness to be open in the statements. The diagnoses of depressive disorder, anxiety, and neurotic spectrum disorders and PDs were assessed by a psychiatrist based on the diagnostic criteria and confirmed by two other qualified psychiatrists. The objectivity in diagnosis was not done using the standard tools such as Mini-International Neuropsychiatric Interview, International Personality Disorder Examination, or The Structured Clinical Interview for DSM-IV Axis II Personality Disorders. Other limitation is that there were no patients with a pure diagnosis of PD without comorbidity of axis I disorder because of the types of psychotherapeutic program. It also needs to be mentioned that the patients were treated with various psychopharmacs and with two alternative psychotherapeutic approaches. Despite this treatment diversity, dissociation proves to be an influential factor contributing to the treatment efficacy of patients with anxiety/neurotic spectrum disorders, depressive disorders, with and without comorbidity with PDs.

\section{Conclusion}

The existing approaches of the treatment cannot help all patients with anxiety/neurotic spectrum disorders and depressive disorders, and a relatively high proportion of them remain resistant to the treatment. It is necessary to search for different therapeutic approaches for reducing the dissociation. If further studies will confirm our findings, this will open up new perspectives for the increasing of the treatment efficacy by the development of new strategies targeted to the reduction of the dissociation.

\section{Disclosure}

The authors report no conflicts of interest in this work.

\section{References}

1. Cooper J, Carty J, Creamer M. Pharmacotherapy for posttraumatic stress disorder: empirical review and clinical recommendations. Aust N Z J Psychiatry. 2005;39(8):674-682.

2. Schmitt R, Gazalle FK, Lima MS, Cunha A, Souza J, Kapczinski F. The efficacy of antidepressants for generalized anxiety disorder: a systematic review and meta-analysis. Rev Bras Psiquiatr. 2005;27(1):18-24.

3. Gartlehner G, Hansen RA, Morgan LC, et al. Comparative benefits and harms of second-generation antidepressants for treating major depressive disorder: an updated meta-analysis. Ann Intern Med. 2011;155(11):772-785.

4. Bandelow B, Reitt M, Röver C, Michaelis S, Görlich Y, Wedekind D. Efficacy of treatments for anxiety disorders: a meta-analysis. Int Clin Psychopharmacol. 2015;30(4):183-192.

5. Baldwin DS, Anderson IM, Nutt DJ, et al. Evidence-based pharmacological treatment of anxiety disorders, post-traumatic stress disorder and obsessive-compulsive disorder: a revision of the 2005 guidelines from the British Association for Psychopharmacology. J Psychopharmacol. 2014;28(5):403-439.

6. Pittenger C, Bloch MH. Pharmacological treatment of obsessivecompulsive disorder. Psychiatr Clin North Am. 2014;37(3):375-391.

7. Maneeton N, Maneeton B, Woottiluk P, et al. Quetiapine monotherapy in acute treatment of generalized anxiety disorder: a systematic review and meta-analysis of randomized controlled trials. Drug Des Devel Ther. 2016;10:259-276.

8. Cuijpers P, van Straten A, Andersson G, van Oppen P. Psychotherapy for depression in adults: a meta-analysis of comparative outcome studies. J Consult Clin Psychol. 2008;76(6):909-922.

9. Blais MA, Malone JC, Stein MB, et al. Treatment as usual (TAU) for depression: a comparison of psychotherapy, pharmacotherapy, and combined treatment at a large academic medical center. Psychotherapy (Chic). 2013;50(1):110-118.

10. Sadeghi R, Mokhber N, Mahmoudi LZ, Asgharipour N, Seyfi H. A systematic review and meta-analysis of controlled treatment trials of metacognitive therapy for anxiety disorders. J Res Med Sci. 2015;20(9): 901-909.

11. Barkowski S, Schwartze D, Strauss B, Burlingame GM, Barth J, Rosendahl J. Efficacy of group psychotherapy for social anxiety disorder: A meta-analysis of randomized-controlled trials. J Anxiety Disord. 2016;39:44-64.

12. de Vries YA, de Jonge P, van den Heuvel E, Turner EH, Roest AM. Influence of baseline severity on antidepressant efficacy for anxiety disorders: metaanalysis and meta-regression. Br J Psychiatry. 2016;208(6):515-521.

13. Pompoli A, Furukawa TA, Imai H, Tajika A, Efthimiou O, Salanti G. Psychological therapies for panic disorder with or without agoraphobia in adults: a network meta-analysis. Cochrane Database Syst Rev. 2016;4:CD011004.

14. Cuijpers P, van Straten A, Warmerdam L, Andersson G. Psychotherapy versus the combination of psychotherapy and pharmacotherapy in the treatment of depression: a meta-analysis. Depress Anxiety. 2009;26(3): 279-288.

15. Hetrick SE, Purcell R, Garner B, Parslow R. Combined pharmacotherapy and psychological therapies for post traumatic stress disorder (PTSD). Cochrane Database Syst Rev. 2010;(7):CD007316. 
16. Romanelli RJ, Wu FM, Gamba R, Mojtabai R, Segal JB. Behavioral therapy and serotonin reuptake inhibitor pharmacotherapy in the treatment of obsessive-compulsive disorder: a systematic review and meta-analysis of head-to-head randomized controlled trials. Depress Anxiety. 2014;31(8):641-652.

17. Huhn M, Tardy M, Spineli LM, et al. Efficacy of pharmacotherapy and psychotherapy for adult psychiatric disorders: a systematic overview of meta-analyses. JAMA Psychiatry. 2014;71(6):706-715.

18. Stimpson N, Agrawal N, Lewis G. Randomised controlled trials investigating pharmacological and psychological interventions for treatmentrefractory depression. Systematic review. Br J Psychiatry. 2002;181: 284-294.

19. Thomas L, Kessler D, Campbell J, et al. Prevalence of treatment-resistant depression in primary care: cross-sectional data. Br J Gen Pract. 2013; 63(617):e852-e858.

20. Fava M. Diagnosis and definition of treatment-resistant depression. Biol Psychiatry. 2003;53(8):649-659.

21. Souery D, Papakostas GI, Trivedi MH. Treatment-resistant depression. J Clin Psychiatry. 2006;67(Suppl 6):16-22.

22. Kubitz N, Mehra M, Potluri RC, Garg N, Cossrow N. Characterization of treatment resistant depression episodes in a cohort of patients from a US commercial claims database. PLoS One. 2013;8(10):e76882.

23. Spijker J, van Straten A, Bockting CL, Meeuwissen JA, van Balkom AJ. Psychotherapy, antidepressants, and their combination for chronic major depressive disorder: a systematic review. Can J Psychiatry. 2013;58(7): 386-392.

24. Nil R, Lütolf S, Seifritz E. Residual symptoms and functionality in depressed outpatients: a one-year observational study in Switzerland with escitalopram. J Affect Disord. 2016;197:245-250.

25. McIntyre RS, Filteau MJ, Martin L, et al. Treatment-resistant depression: definitions, review of the evidence, and algorithmic approach. $J$ Affect Disord. 2014;156:1-7.

26. Watson S, Chilton R, Fairchild H, Whewell P. Association between childhood trauma and dissociation among patients with borderline personality disorder. Aust N Z J Psychiatry. 2006;40(5):478-481.

27. Prasko J, Raszka M, Adamcova K, et al. Predicting the therapeutic response to cognitive behavioral therapy in patients with the pharmacoresistant obsessive-compulsive disorder. Neuroendocrinol Lett. 2009;30(5):615-623.

28. Ociskova M, Prasko J, Kamaradova D, Grambal A, Latalova K, Sigmundova Z. Relationship between internalized stigma and treatment efficacy in the mixed neurotic spectrum and depressive disorders. Neuro Endocrinol Lett. 2015;35(8):711-717.

29. Zanarini MC, Ruser T, Frankenburg FR, Hennen J. The dissociative experiences of borderline patients. Compr Psychiatry. 2000;41(3): 223-227.

30. Spiegel D, editor. Dissociation. Washington, DC: American Psychiatric Press; 1994

31. Orne MT. The nature of hypnosis: artifact and essence. J Abnorm Psychol. 1959;58(3):277-299.

32. Spiegel H, Spiegel D. Trance and Treatment: Clinical Uses of Hypnosis. Washington, DC: American Psychiatric Press; 1987.

33. Maldonado J, Spiegel D. Trauma, dissociation, and hypnotizability. In: Marmar R, Bremner D, editors. Trauma, Memory, and Dissociation. Washington, DC: American Psychiatric Press; 1998.

34. Janoff-Bulman R. Shattered Assumptions. New York: The Free Press; 1992.

35. McCann IL, Pearlman LA. Psychological Trauma and the Adult Survivor. New York: Bruner/Mazel; 1990.

36. Putnam FW. Traumatic stress and pathological dissociation. Ann N Y Acad Sci. 1995;771:708-715.

37. Bremner JD, Brett E. Trauma-related dissociative states and long-term psychopathology in posttraumatic stress disorder. J Trauma Stress. 1997; 10(1):37-49.

38. Ahrens CE, Aldana E. The ties that bind: understanding the impact of sexual assault disclosure on survivors' relationships with friends, family, and partners. J Trauma Dissociation. 2012;13(2):226-243.
39. Maldonado J, Spiegel D. Treatment of post traumatic stress disorder. In: Lynn S, Rhue J, editors. Dissociation: Clinical, Theoretical, and Research Perspectives. New York, NY: Guilford Press; 1994:215-241.

40. Draijer N, Langeland W. Childhood trauma and perceived parental dysfunction in the etiology of dissociative symptoms in psychiatric inpatients. Am J Psychiatry. 1999;156(3):379-385.

41. Simeon D, Guralnik O, Schmeidler J, Sirof B, Knutelska M. The role of childhood interpersonal trauma in depersonalization disorder. Am J Psychiatry. 2001;158(7):1027-1033.

42. Roy A. Childhood trauma and neuroticism as an adult: possible implication for the development of the common psychiatric disorders and suicidal behavior. Psychol Med. 2002;32:1471-1474.

43. McFarlane A, Clark CR, Bryant RA, et al. The impact of early life stress on psychophysiological, personality and behavioral measures in 740 non-clinical subjects. J Integr Neurosci. 2005;4(1):27-40.

44. Stein MB, Schork NJ, Gelernter J. Gene-by-environment (serotonin transporter and childhood maltreatment) interaction for anxiety sensitivity, an intermediate phenotype for anxiety disorders. Neuropsychopharmacology. 2008;33(2):312-319.

45. Epstein S. The self-concept, the traumatic neurosis, and the structure of personality. In: Ozer D, Healy JM Jr, Stewart AJ, Editors. Perspectives in Personality. (vol 3A). London: Jessica Kingsley; 1991:63-98.

46. Tyrer P, Davidson K. Management of personality disorder. In: Gelder MG, Lopez-Ibor JJ, Andreasen A, editors. New Oxford Textbook of Psychiatry. Oxford: Oxford University Press; 2000:970-978.

47. Perry JC, Bond M. Empirical studies of psychotherapy for personality disorders. In: Gunderson JG, Gabbard GO, editors. Psychotherapy for Personality Disorders, Review of Psychiatry Series 19/3. Washington DC: American Psychiatric Press; 2000:1-32.

48. Prasko J, Houbova P, Novak T, et al. Influence of personality disorder on the treatment of panic disorder - comparison study. Neuro Endocrinol Lett. 2005;26(6):667-674.

49. Vyskocilova J, Prasko J, Novak T, Pohlova L. Is there any influence of personality disorder on the short term intensive group cognitive behavioral therapy for social phobia? Biomed Pap Med Fac Univ Palacky Olomouc Czech Repub. 2011;155(1):85-94.

50. Kamaradova D, Prasko J, Sandoval A, Latalova K. Therapeutic response to complex cognitive-behavioral and pharmacological treatment in patients with social phobia. Act Nerv Super Rediviva. 2014;56(3-4):91-99.

51. Kamarádová D, Praško J, Grambal A, et al. Predictors of therapeutic response in patients with panic disorder identified by demographic and clinical data. [Prediktory terapeutické odpovědi pacientů s panickou poruchou identifikované pomocí demografických a klinických dat]. Čes A Slov Psychiat. 2013;109:577-583. Czech.

52. Sedlackova Z, Prasko J, Latalova K, et al. Psychosocial aspects of resistance in complex treatment of depressive disorder. Neuro Endocrinol Lett. 2015;36(4):354-362.

53. Russell JM, Kornstein SG, Shea MT, et al. Chronic depression and comorbid personality disorders: response to sertraline versus imipramine. J Clin Psychiatry. 2003;64(5):554-561.

54. Kool S, Schoevers R, de Maat S, et al. Efficacy of pharmacotherapy in depressed patients with and without personality disorders: a systematic review and meta-analysis. J Affect Disord. 2005;88(3):269-278.

55. Blom MB, Spinhoven P, Hoffman T, et al. Severity and duration of depression, not personality factors, predict short term outcome in the treatment of major depression. J Affect Disord. 2007;104(1-3):119-126.

56. Maddux RE, Riso LP, Klein DN, et al. Select comorbid personality disorders and the treatment of chronic depression with nefazodone, targeted psychotherapy, or their combination. J Affect Disord. 2009;117(3): 174-179.

57. Sato T, Sakado K, Sato S, Morikawa T. Cluster a personality disorder: a marker of worse treatment outcome of major depression? Psychiatry Res. 1994;53(2):153-159.

58. Bagby RM, Quilty LC, Segal ZV, McBride CC, Kennedy SH, Costa PT. Personality and differential treatment response in major depression: a randomized controlled trial comparing cognitive-behavioural therapy and pharmacotherapy. Can J Psychiatry. 2008;53(6):361-370. 
59. Levenson JC, Wallace ML, Fournier JC, Rucci P, Frank E. The role of personality pathology in depression treatment outcome with psychotherapy and pharmacotherapy. J Consult Clin Psychol. 2012;80(5):719-729.

60. O'Leary D, Costello F. Personality and outcome in depression: an 18-month prospective follow-up study. J Affect Disord. 2001;63(1-3): 67-78.

61. Galione J, Zimmerman M. A comparison of depressed patients with and without borderline personality disorder: implications for interpreting studies of the validity of the bipolar spectrum. J Pers Disord. 2010;24(6): 763-772.

62. Prasko J, Latalova K, Diveky T, et al. Panic disorder, autonomic nervous system and dissociation - changes during therapy. Neuro Endocrinol Lett. 2011;32(5):641-651.

63. Mezinárodní klasifikace nemocí. 10. revize. [International Classification of the Diseases - 10th edition] Duševní poruchy a poruchy chování: Diagnostická kritéria pro výzkum. (přeloženo z anglického originálu). Praha: Psychiatrické centrum; 1996. Czech.

64. Storch EA, Roberti JW, Roth DA. Factor structure, concurrent validity, and internal consistency of the beck depression inventory - second edition in a sample of college students. Depress Anxiety. 2004;19(3): 187-189.

65. Preiss M, Vacir K. Beckova sebeposuzovací škála depresivity pro dospělé - BDI-II [Beck Self-Report Depression Scale for Adults BDI-II]. Brno: Psychodiagnostika; 1999.

66. Guy W, editor. ECDEU Assessment Manual for Psychopharmacology. Rockville, US: DHEW; 1976.

67. Zaider TI, Heimberg RG, Fresco DM, Schneier FR, Liebowitz MR. Evaluation of the Clinical global impression scale among individuals with social anxiety disorder. Psychol Med. 2003;33(4):611-622.

68. Beck AT, Epstein N, Brown G, Steer RA. An inventory for measuring clinical anxiety: psychometric properties. J Consult Clin Psychol. 1988; 56:893-897.

69. De Ayala RJ, Vonderharr-Carlson DJ, Kim D. Assessing the reliability of the Beck Anxiety Inventory scores. Educ Psychol Meas. 2005; 65(5):742-756.

70. Kamaradova D, Prasko J, Latalova K, et al. Psychometric properties of the Czech version of the Beck Anxiety Inventory - comparison between diagnostic groups. Neuro Endocrinol Lett. 2015;36(7):706-712.

71. Sheehan DV, Raj AB, Sheehan KH, Soto S. The relative efficacy of buspirone, imipramine and placebo in panic disorder: a preliminary report. Pharmacol Biochem Behav. 1988;29(4):815-817.

72. Sheehan DV. Sheehan Patient-Related Anxiety Scale. In: McGlynn TJ, Metcalf HL, editors. Diagnosis and Treatment of Anxiety Disorders: A Physician's Handbook. Washington, DC; American Psychiatric Press, Inc; 1989:98-99.

73. Kick SD, Bell JA, Norris JM, Steiner JF. Validation of two anxiety scales in a university primary care clinic. Psychosom Med. 1994;56(6): 570-576.

74. Bernstein EM, Putnam FW. Development, reliability, and validity of a dissociation scale. J Nerv Ment Dis. 1986;174(12):727-735.

75. Spitzer C, Freyberger H, Brähler E, Beutel ME, Stieglitz R. [Psychometric evaluation of the Dissociative Experiences Scale-Taxon (DES-T)] Psychother Psychosom Med Psychol. 2015;65(3-4):134-139.

76. Waller NG, Ross CA. The prevalence and biometric structure of pathological dissociation in the general population: taxometric and behavior genetic findings. J Abnorm Psychol. 1997;106(4):499-510.

77. Ptacek R, Bob P, Paclt I. Škála disociativních zkušeností - česká verze [Dissociative Experiences Scale - Czech version]. Československa Psychol. 2006;50(3):262-272. Czech.

78. EMEA, 2002. Available from: http://www.ema.europa.eu/docs/en_GB/ document_library/Scientific_guideline/2009/09/WC500003526.pdf. Accessed August 25, 2016.
79. Prasko J, Kamaradova D, Cakirpaloglu S, et al. Predicting the therapeutic response to intensive psychotherapeutic programs in patients with neurotic spectrum disorders. Act Nerv Super Rediviva. 2015;57(1-2): 30-39.

80. Thomas LJ, Abel A, Ridgway N, et al. Cognitive behavioural therapy as an adjunct to pharmacotherapy for treatment resistant depression in primary care: the CoBalT randomised controlled trial protocol. Contemp Clin Trials. 2012;33(2):312-319.

81. Hollinghurst S, Carroll FE, Abel A, et al. Cost-effectiveness of cognitive-behavioural therapy as an adjunct to pharmacotherapy for treatment resistant depression in primary care: economic evaluation of the CoBalT Trial. Br J Psychiatry. 2014;204(1):69-76.

82. Wiles N, Thomas L, Abel A, et al. Clinical effectiveness and cost-effectiveness of cognitive behavioural therapy as an adjunct to pharmacotherapy for treatment resistant depression in primary care: the CoBalT randomised controlled trial. Health Technol Assess. 2014;18(31): $1-167$.

83. van der Lem R, Stamsnieder PM, van der Wee NJ, van Veen T, Zitman FG. Influence of sociodemographic and socioeconomic features on treatment outcome in RCTs versus daily psychiatric practice. Soc Psychiatry Psychiatr Epidemiol. 2013;48(6):975-984.

84. Jakubovski E, Bloch MH. Prognostic subgroups for citalopram response in the STAR*D trial. J Clin Psychiatry. 2014;75(7):738-747.

85. Quilty LC, Mainland BJ, McBride C, Bagby RM. Interpersonal problems and impacts: further evidence for the role of interpersonal functioning in treatment outcome in major depressive disorder. $J$ Affect Disord. 2013;150(2):393-400.

86. Husain MM, Rush AJ, Wisniewski SR, et al. Family history of depression and therapeutic outcome: findings from STAR*D.J Clin Psychiatry. 2009;70(2):185-195.

87. Knorr UB. The effect of selective serotonin reuptake inhibitors in healthy first-degree relatives of patients with major depressive disorder - an experimental medicine blinded controlled trial. Dan Med J. 2012;59(4):B4426.

88. De Carlo V, Calati R, Serretti A. Socio-demographic and clinical predictors of non-response. Non-remission in treatment resistant depressed patients: a systematic review. Psychiatry Res. 2016;240:421-430.

89. Pitman SR, Hilsenroth MJ. Interpersonal subtypes of anxiety disorder patients: relationship to assessment and treatment variables. J Nerv Ment Dis. 2016;204(7):513-518.

90. Gorwood P, Rouillon F, Even C, Falissard B, Corruble E, Moran P. Treatment response in major depression: effects of personality. $\mathrm{Br} J$ Psychiatry. 2010;196(2):139-142.

91. Cooper AA, Conklin LR. Dropout from individual psychotherapy for major depression: a meta-analysis of randomized clinical trials. Clin Psychol Rev. 2015;40:57-65.

92. Pozza A, Andersson G, Dèttore D. What does best evidence tell us about the efficacy of group cognitive-behavioral therapy for obsessive-compulsive disorder? Protocol for a systematic review and meta-analysis. Psychol Res Behav Manag. 2015;8:225-230.

93. van Minnen A, Zoellner LA, Harned MS, Mills K. Changes in comorbid conditions after prolonged exposure for PTSD: a literature review. Curr Psychiatry Rep. 2015;17(3):549.

94. Lorentzen S, Ruud T, Fjeldstad A, Høglend PA. Personality disorder moderates outcome in short- and long-term group analytic psychotherapy: a randomized clinical trial. Br J Clin Psychol. 2015;54(2):129-146.

95. Rufer M, Fricke S, Held D, Cremer J, Hand I. Dissociation and symptom dimensions of obsessive-compulsive disorder: a replication study. Eur Arch Psychiatry Clin Neurosci. 2006;256(3):146-150.

96. Gulsun M, Doruk A, Uzun O, Turkbay T, Ozsahin A. Effect of dissociative experiences on drug treatment of panic disorder. Clin Drug Investig. 2007;27(8):583-590. 


\section{Publish your work in this journal}

Neuropsychiatric Disease and Treatment is an international, peerreviewed journal of clinical therapeutics and pharmacology focusing on concise rapid reporting of clinical or pre-clinical studies on a range of neuropsychiatric and neurological disorders. This journal is indexed on PubMed Central, the 'PsycINFO' database and CAS,

and is the official journal of The International Neuropsychiatric Association (INA). The manuscript management system is completely online and includes a very quick and fair peer-review system, which is all easy to use. Visit http://www.dovepress.com/testimonials.php to read real quotes from published authors.

Submit your manuscript here: http://www.dovepress.com/neuropsychiatric-disease-and-treatment-journal 